\title{
Large-area formation of microsphere arrays using laser surface texturing
} technology

Yue, Liyang; Monks, James; Yan, Bing; Wang, Zengbo

\section{Applied Physics A: Materials Science and Processing}

DOI:

10.1007/s00339-017-0946-x

Published: 01/05/2017

Peer reviewed version

Cyswllt i'r cyhoeddiad / Link to publication

Dyfyniad o'r fersiwn a gyhoeddwyd / Citation for published version (APA):

Yue, L., Monks, J., Yan, B., \& Wang, Z. (2017). Large-area formation of microsphere arrays using laser surface texturing technology. Applied Physics A: Materials Science and Processing, 123, [318]. https://doi.org/10.1007/s00339-017-0946-x

\footnotetext{
Hawliau Cyffredinol / General rights

Copyright and moral rights for the publications made accessible in the public portal are retained by the authors and/or other copyright owners and it is a condition of accessing publications that users recognise and abide by the legal requirements associated with these rights.

- Users may download and print one copy of any publication from the public portal for the purpose of private study or research.

- You may not further distribute the material or use it for any profit-making activity or commercial gain

- You may freely distribute the URL identifying the publication in the public portal ?
}

Take down policy

If you believe that this document breaches copyright please contact us providing details, and we will remove access to the work immediately and investigate your claim. 


\title{
Large-area formation of microsphere arrays by using laser surface texturing technology
}

\author{
Liyang Yue ${ }^{1}$, James Norman Monks ${ }^{1}$, Bing Yan $^{1}$, and Zengbo Wang ${ }^{1}$ \\ ${ }^{1}$ School of Electronic Engineering, Bangor University, Bangor, LL57 1UT, UK
}

Corresponding authors. E-mail addresses: 1.yue@bangor.ac.uk (L. Yue).z.wang@bangor.ac.uk (Z. B. Wang)

Keywords: microsphere arrays, particle arrangement, laser surface texturing, pulsed laser

\begin{abstract}
Many potential applications in optics and nanotechnology require arrays of spherical particles with dozens of microns diameter, but it is not easy to format microspheres in this scale using existing technologies, especially for large-area application. In this paper, we report that microspheres sized from 40 to $80 \mu \mathrm{m}$ can be regularly arranged in arrays with the aid of micro-ridges generated by pulsed nanosecond (ns) laser texturing. After experimental comparison, it is known that final formation of microspheres is significantly related to the height and width of micro-ridges. Proposed particle arrangement technology does not have area limitation and harsh hardware requirement, simultaneously possessing low-cost and time-saving advantages.
\end{abstract}

\section{Introduction}

Ordered arrays of particles with demanded properties are expected to find applications in diverse fields, including sensors [1-3], photonic lithography [4-5], generation of photonic nanojets [6, 7], etc. For this reason, various technologies were invented to fabricate tailored arrays for multiple sized and shaped particles. For smaller nanoparticles or particles in several microns scale, guided-assembly and self-assembly are common methods to obtain their regular arrangement. In this manner, capillary force drags nanoparticles out of their solution at interface and place them into a monolayer with hexagonal assembly during drying $[8,9]$. Following arrays are normally shaped by using chemicaletched or lithographed templates [10-13], and a slow-motion stage is occasionally needed to pull out vertically placed substrate for processing of nanoparticles with specific scale [8]. This process is difficult to apply to relatively large particles ( $>10 \mu \mathrm{m}$ diameter) and commonly consumes dozens of hours. Optical trapping or optical tweezers is another technique to move and capture single or multiple particles through an attractive or repulsive force from a highly focused laser beam $[14,15]$. However, compared to guided or self-assembly technology, observation and laser aiming for optical trapping is time-consuming, and regarding particle moving is individually performed, which results in size limitation of processing area although usage of galvo-scanner accelerates arrangement process for particular applications [16]. Besides, fast arrangement of particles over large-area is also challenging for mechanical positioning methods which typically use probe of Atomic Force Microscopy (AFM) or piezo-based robotic manipulator to push particles to targeted positions [17, 18].

Laser surface texturing technology has emerged in 1990s as a viable option of surface engineering that originally aims to improve tribological performance of material surface, e.g. load capacity, wear resistance, and friction coefficient [19]. In this paper, we innovatively invent its new application microspheres arrangement. Pulsed ns fibre laser is used to produce micro-ridges formed by continuous thermal bumps on the surface of 1100 aluminium (Al) alloy. It is found that Barium Titanate $\left(\mathrm{BaTiO}_{3}\right)$ microspheres in 40 to $80 \mu \mathrm{m}$ diameter can be naturally arranged in arrays on laser textured surface after free-fall. Large-area formation can be finished in minutes using proposed technology, and there is no particle solution or chemical solvent involving in the experiment.

\section{Experiments}

A pulsed IPG YPLN ns fibre laser (power: $10 \mathrm{w}$, pulse duration: $100 \mathrm{~ns}$, wavelength: $1064 \mathrm{~nm}$, repetition rate range: $20-200 \mathrm{kHz}$ ) was used as laser source to texture the surface of Al alloy plate. Experimental layout is shown in Fig. 1 (a). Beam path is visually designed by a laser operation software and controlled by a galvo scanner with $160 \mathrm{~mm}$ focal length. Al alloy target is placed on a 
manual stage at the height of laser focal plane. Laser treatment area can be indicated by a red colour pilot beam before opening of main beam. Once texturing starts, programmable servo motors will drive two reflection mirrors, $x$ mirror and $y$ mirror, to rotate in galvo scanner, which respectively guide laser beam in transverse ( $x$ axis) and longitudinal ( $y$ axis) directions, as shown in Fig. 1 (b). Beam paths are structured as parallel lines with same distance. The laser spot size is $50 \mu \mathrm{m}$, and scanning area wider than this value is made up by overlapped one-pass scan. In this paper, all results are collected by using $85 \%$ laser power and $100 \mathrm{kHz}$ repetition rate. Height and width of micro-ridges on $\mathrm{Al}$ alloy surface are tuned by beam moving speed and width of scanning area. Also, $\mathrm{BaTiO}_{3}$ microspheres $(40-80 \mu \mathrm{m}$ diameter) can be applied on laser textured surface by using a simple cotton swab, whose fibres is able to wind microspheres and make them drop after slight shaking, as shown in Fig. 1 (c). The distance between cotton swab and $\mathrm{Al}$ alloy target should be over $20 \mathrm{~mm}$ to secure even distribution of particles through free-fall, meanwhile operator had better avoid spill redundant particles at the same location, in case particle stacking.

Two sets of experiments are performed in this paper to respectively quantify the influence of height and width changes of micro-ridges for microsphere arrangement. Multiple formations of microspheres are demonstrated varying diverse heights and widths of micro-ridges in this process. Dimension of micro-ridges/slots is directly measured by using an upright optical microscope equipped with digital camera. In black-white optical microscope pictures, laser scanned area is in black colour. Consequently, micro-ridge width can be measured as width of black line in captured pictures. Height of micro-ridges and depth of micro-slot are determined by difference between focal plane of ridges top/slot bottom and normal untextured $\mathrm{Al}$ alloy surface. In this manner, imaging focus of microscope will be fixed at ridges top or slots bottom to record first read of focal length, then slowly move down/up to seek Al alloy surface without texturing to make second read of focal length. Corresponding displacement of two reads is automatically calculated by microscope control software and considered as the height of micro-ridge and depth of micro-slot. Laser texturing area is $10 \mathrm{~mm} \times$ $10 \mathrm{~mm}$ for every parameter combination - micro-ridge width and height (texturing area could be much larger than this value; this size is for saving base material in the experiment). Means of parameters are recorded after 20 times measurements of micro-ridge/slot heights and depth, and error bars are given in the statistical figure. Scanning electron microscope (SEM) pictures are exhibited to show morphologies of $\mathrm{Al}$ alloy surface processed by pulsed laser using multiple scanning speeds.
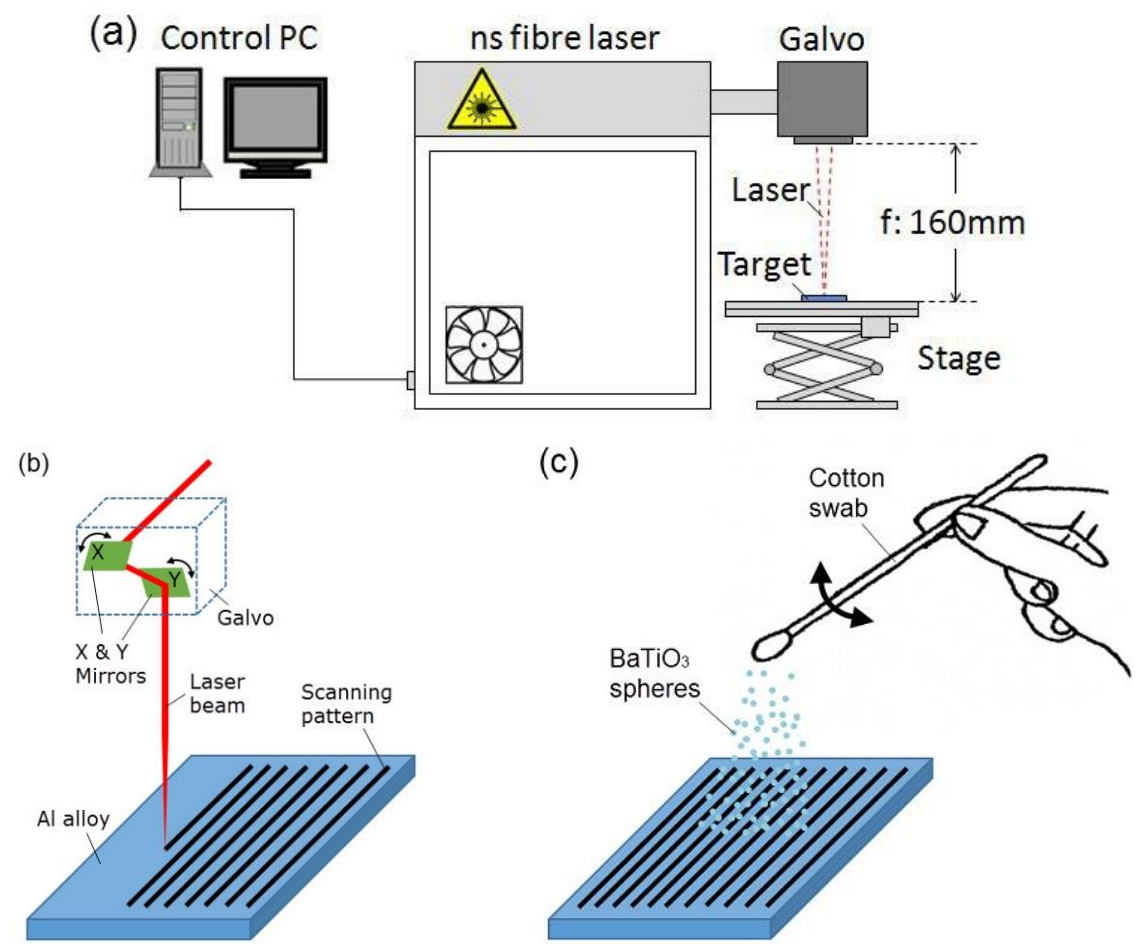

Fig. 1. (a) Experimental layout (b) Beam movement of laser texturing technology (c) Distribution of $\mathrm{BaTiO}_{3}$ microspheres in laser processed area 


\section{Results and discussions}

\subsection{Micro-ridges height}

Fig. 2 (a-d) show the effects of microspheres arrangements on the $\mathrm{Al}$ alloy surface textured by laser with 300, 100, 40 and $20 \mathrm{~mm} / \mathrm{s}$ scanning speed, respectively. All scanning lines are finished by nonoverlapping single pass scan with about $50 \mu \mathrm{m}$ widths in this set. After multi-times measurement, heights of micro-ridge average to 2,12, 24 and $30 \mu \mathrm{m}$ for scanning speeds of 300, 100, 40 and 20 $\mathrm{mm} / \mathrm{s}$, respectively, pairing of 10,20, 23 and $23 \mu \mathrm{m}$ micro-slot depths. To distinguish formatted particle arrays from randomly spilled particles, pictures in Fig. 2 are captured at the boundary of laser treated area as greyscale images to maximize contrast. For this reason, laser scanning route (left side) is displayed as dark colour in Fig. 2, while untreated area (right side) and transparent $\mathrm{BaTiO}_{3}$ particles show bright and grey colours. Generally, compared to random distribution in right side of pictures, microspheres arrangements are varied for changes of laser scanning speed in left side of pictures consisting of dark and bright stripes. In Fig. 2 (a) and (b), no distributional difference is observed for microspheres in the area textured by $300 \mathrm{~mm} / \mathrm{s}$ and $100 \mathrm{~mm} / \mathrm{s}$ pulsed laser (left side). Amounts of particles in dark and bright stripes are similar. Subsequently, it is found that microsphere distribution starts to concentrate in bright stripes with decrease of laser scanning speed from $100 \mathrm{~mm} / \mathrm{s}$. Two typical pictures are shown in Fig. 2 (c) and (d). Fig. 2 (c) processed by $40 \mathrm{~mm} / \mathrm{s}$ laser beam indicates that majority of microspheres already settle in the bright stripes area, but several particles can still be seen in dark stripes. Further lowering scanning speed to $20 \mathrm{~mm} / \mathrm{s}$ all microspheres are to be found in arrays in bright stripes, as shown in Fig. 2 (d), which is in sharp contrast with the great dispersion of particles in the right of picture for laser untreated area.
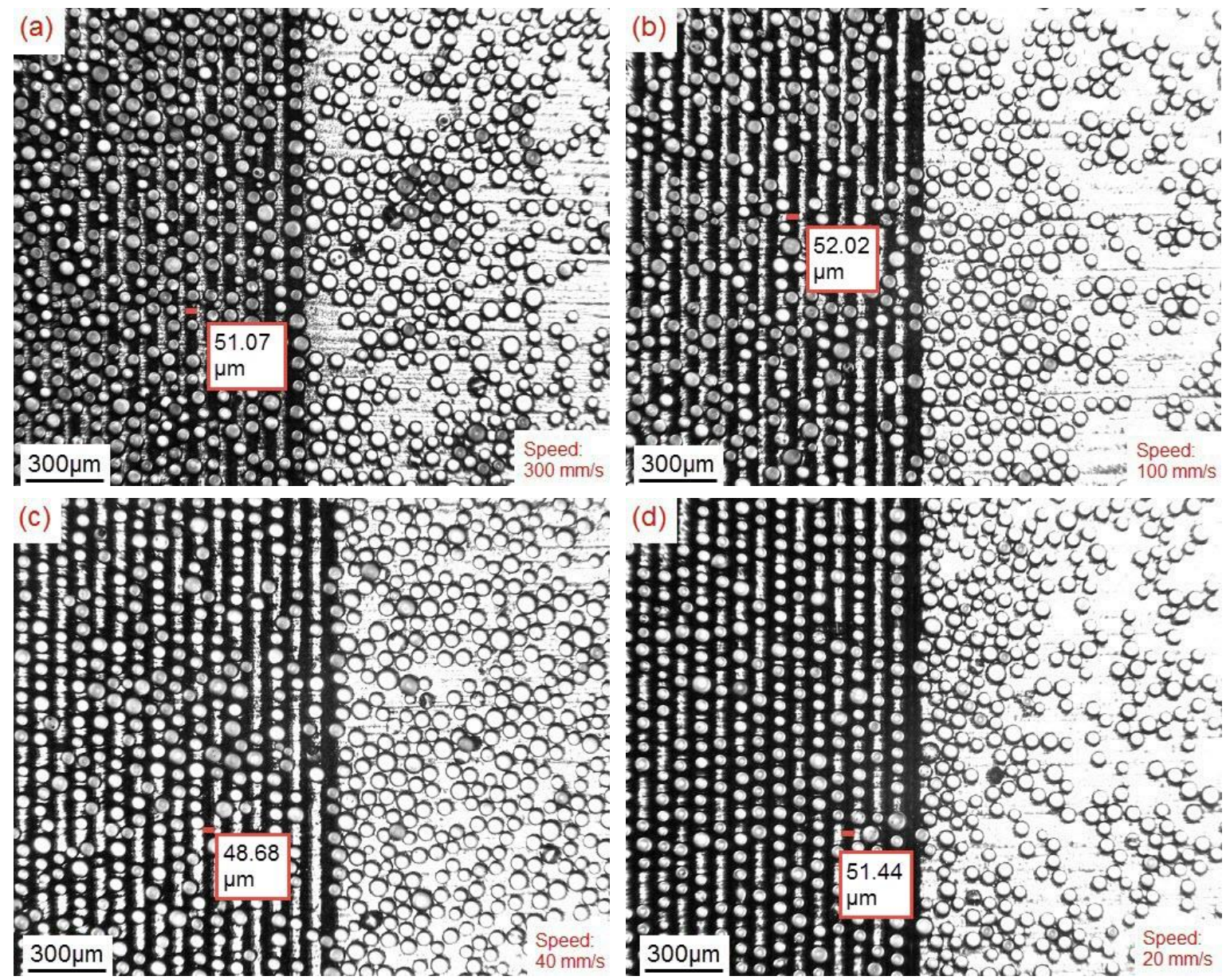

Fig. 2. Effects of microspheres arrangements at laser scanning speed $300 \mathrm{~mm} / \mathrm{s} \mathrm{(a),} 100 \mathrm{~mm} / \mathrm{s}$ (b), 40 $\mathrm{mm} / \mathrm{s}(\mathrm{c})$ and $20 \mathrm{~mm} / \mathrm{s}(\mathrm{d})$

It is well known that height of thermal bumps is corresponding to the laser scanning speed under the same laser settings of power $(85 \%)$ and repetition rate $(100 \mathrm{kHz})$ in this case. Most of time thermal bumps are considered as faults of laser ablation and other laser surface techniques $[20,21]$. The 
physics behind this phenomenon is phase-change of metals due to temperature rise. Residual heat inputted from pulsed laser melt small portion of material, which leads to instantly solidified microridges caused by ejection of molten metal following the vaporisation of metal in central scanning area (micro-slot forming) [21]. Here we switch micro-ridges formed by continuous thermal bumps from 'drawbacks' into main functional patterns. Slow laser scanning speed aggravates heat affection and ejection of molten metal, which effectively increase the height of micro-ridges and produce slopes on both sides due to accumulation of ejected material (surface debris). Heights of micro-ridges and depth of micro-slots induced by laser texturing are summarised against multiple scanning speeds in Fig. 3 (a). It is shown that ridge height (red scatters) has a sharp growth since scanning speed is lower than $150 \mathrm{~mm} / \mathrm{s}$. Micro-ridge height approximates to $10 \mu \mathrm{m}$ at $100 \mathrm{~mm} / \mathrm{s}$ scanning speed, and then quickly increases to about 26 and $32 \mu \mathrm{m}$ at 20 and $10 \mathrm{~mm} / \mathrm{s}$, respectively. Meanwhile, distribution of microslot depth scatters is more linear, and values for speed below $100 \mathrm{~mm} / \mathrm{s}$ are similar and converge around $24 \mu \mathrm{m}$. Above mentioned trends of ridge height and slot depth reflect on SEM pictures shown in Fig. 3 (b-e) representing scanning speed 300, 100, 40 and $20 \mathrm{~mm} / \mathrm{s}$, respectively. For high speed scanning, there is no obvious bumps found at the edges of central material removal in Fig. 3 (b), but height growth of edges is observed in Fig. 3 (c-e), especially for speed $20 \mathrm{~mm} / \mathrm{s}$, bumps at both sides approach to centre to form a sloped micro-ridge much higher than the substrate.

A diagram of microspheres settlement is shown in Fig. 3 (f). Once sufficiently high micro-ridges are generated, such as ones in Fig. 3 (e), there will be two scenarios for free fallen microspheres depending on their original positions in the air, marked as circle 1 and 2 (dashed circles) in Fig. 3 (f) representing positions above non-laser-textured stripe and laser-textured stripe, respectively. Particle arrays are only arranged in non-laser-treated stripes (bright stripes in Fig. 2). In diagram this settlement position (SP) is shown as an orange colour sphere between aside micro-ridges. Particles fallen from position 1 are able to land to SP directly, otherwise particles from position 2 needs to contact micro-ridges at first, then roll to SP due to gravity. However, microspheres from position 2 are possible to stop on the top of micro-ridges because of low height and insufficient slope angle. For this reason, it is known that formation of microsphere arrays cannot be achieved on the surface textured by a high-speed laser beam, which is in accordance with pictures of particle arrangements shown in Fig. 2 and dimensional data of micro-ridges summarised in Fig. 3 (a).

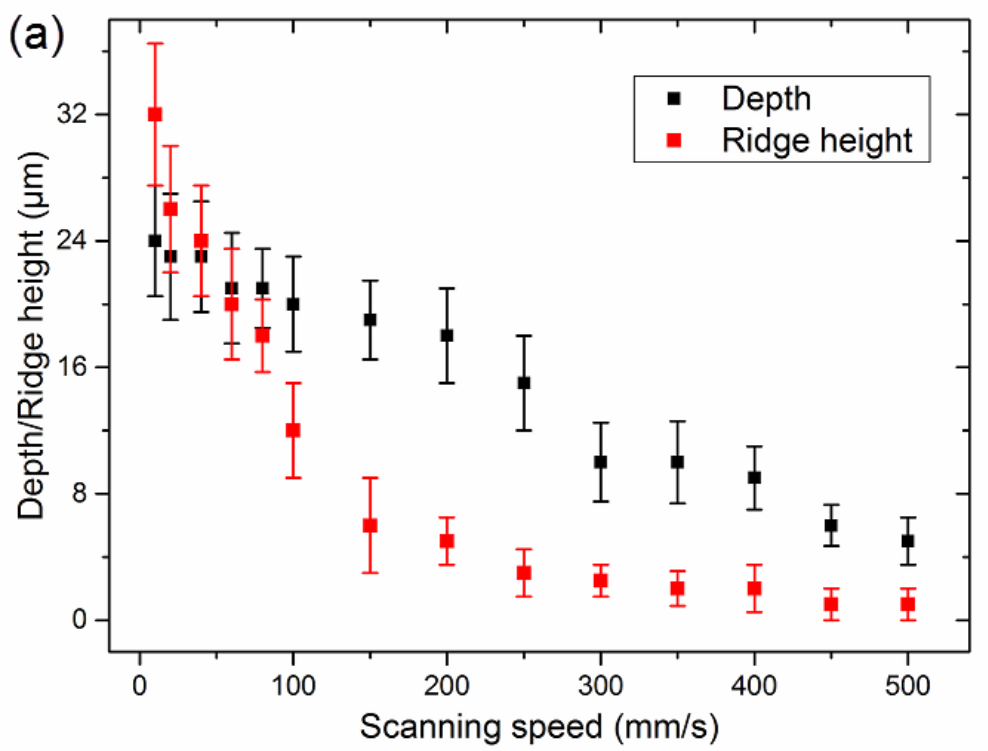



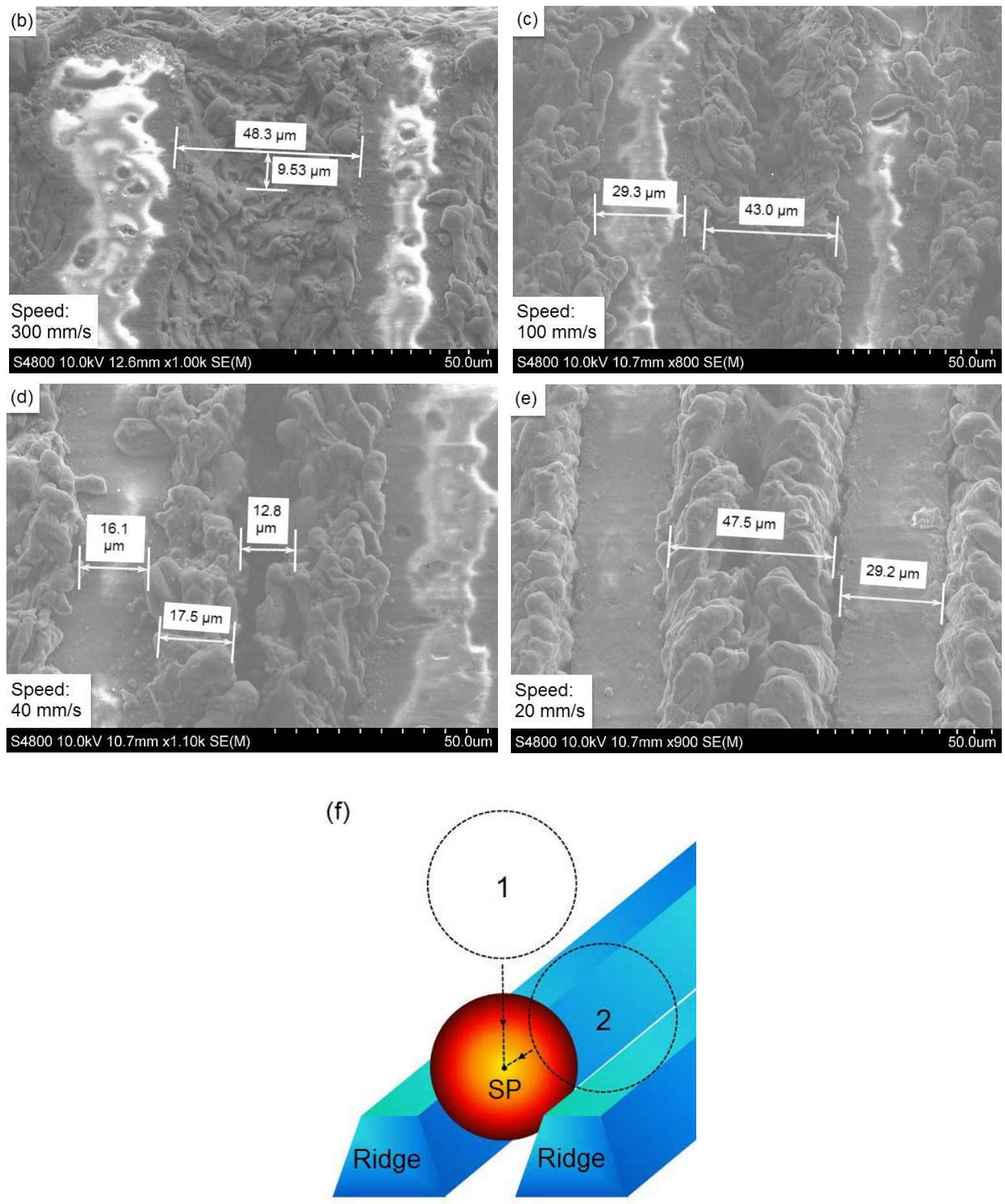

Fig. 3. (a) Statistics for heights of micro-ridges and depths of micro-slots induced by laser scanning (b-e) SEM pictures of scanning area for beam moving speed 300, 100, 40 and $20 \mathrm{~mm} / \mathrm{s}$, respectively (f) diagram to demonstrate microspheres settlement after free-fall

\subsection{Micro-ridges width}

To further study mechanism of particle arrangement, influence of micro-ridges width change is also experimentally investigated. Fig. 4 (a-c) shows the effects of particle arrangement on micro-ridges with 50,100 , and $150 \mu \mathrm{m}$ widths. Laser scanning speed is fixed at $20 \mathrm{~mm} / \mathrm{s}$. Multi-pass scan of laser beam is used to achieve micro-ridges wider than beam spot size $-50 \mu \mathrm{m}$. Overlapping rate, $\eta$, is defined to describe and control the distribution of laser treated area on the Al alloy surface, which is expressed as [22], 


$$
\eta=\frac{\Delta}{D} \times 100 \%
$$

where $D$ is the beam spot diameter, $\Delta$ is overlapping length of two successive beam spots, and $50 \%$ overlapping rate is applied to this set of experiment. Micro-ridge height and micro-slot depth are slightly larger than the single-pass data shown in Fig. 3 (a) due to overlapping scanning, averaging to $33 \mu \mathrm{m}$ and $27 \mu \mathrm{m}$, respectively. For $50 \mu \mathrm{m}$ wide micro-ridges shown in Fig. 4 (a) mechanism of particle arrangement is gravity-driven rolling as the illustration in Fig. 3 (f). If width of micro-ridges is doubled to $100 \mu \mathrm{m}$, it is found that a few of particles start to settle on the top of micro-ridges (dark stripes). Clearer trend is observed for the particles arranged on $150 \mu \mathrm{m}$ wide micro-ridges, and regarding random distribution is shown on the left side of Fig. 4 (c). Settlement process on wide micro-ridges is shown in Fig. 4 (d). Formation difference between narrow and wide micro-ridges is depending on the microspheres dropping from position 2 - over laser-textured stripe, marked in Fig. 3 (f) and Fig. 4 (d). Due to larger top area, there is no gravity-driven rolling happening for microspheres from position 2, instead of direct settlement on wide micro-ridge top, as shown in Fig. 4 (d). A mixedwidths experiment is designed to verify above mentioned mechanism, as shown in Fig. 4 (e). 50 and $100 \mu \mathrm{m}$ wide micro-ridges are alternating patterns produced on Al alloy surface. Majority of microspheres is on bright stripe (untreated area). Only several particles can be seen on $100 \mu \mathrm{m}$ wide black stripes (micro-ridges), but none of them locates on $50 \mu \mathrm{m}$ narrow black stripe.
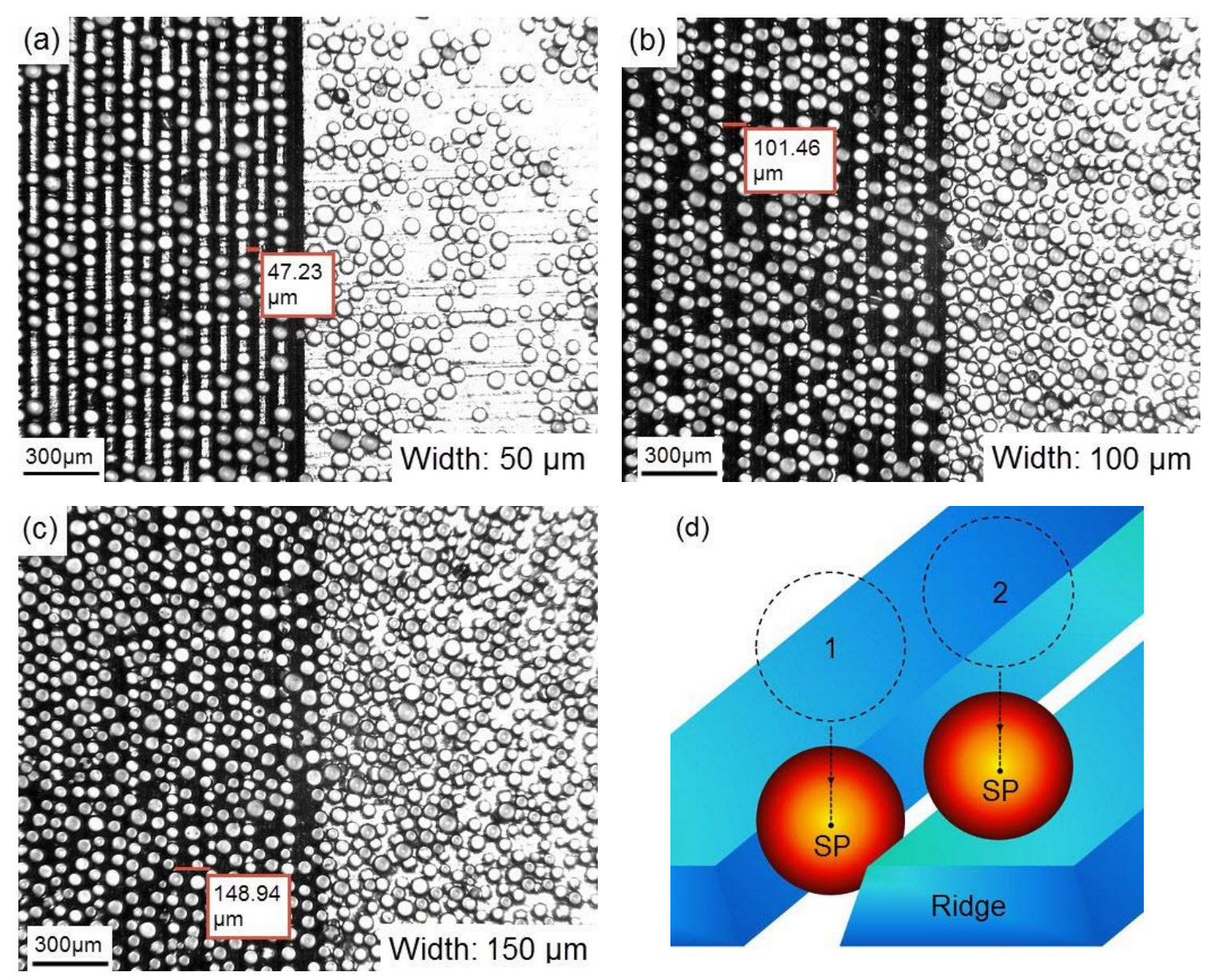


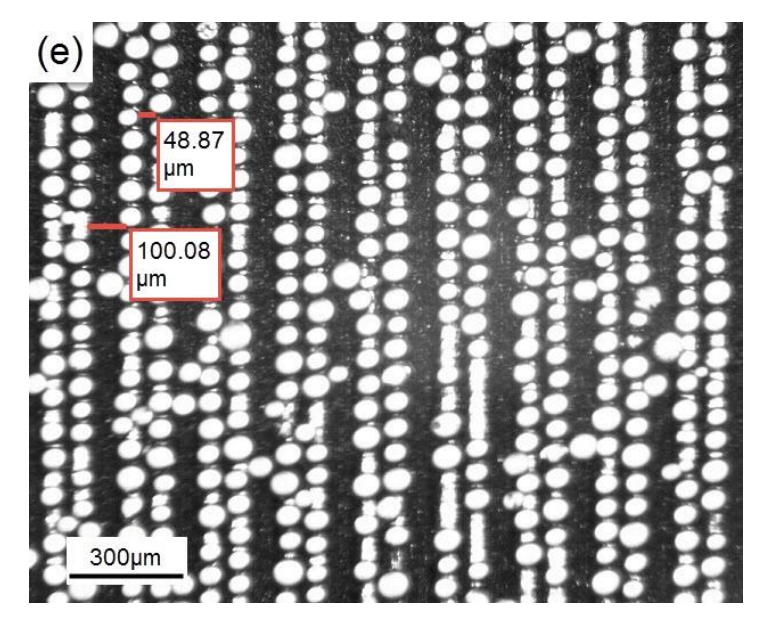

Fig. 4. (a-c) Effects of particle arrangement on micro-ridges with 50, 100, and $150 \mu \mathrm{m}$ widths, respectively (d) Diagram of particle settlement on wide micro-ridges area (e) Effect of particle arrangement on mixed-widths micro-ridges

\section{Conclusions}

The results presented in this work show that with the aid of laser surface texturing technology $\mathrm{BaTiO}_{3}$ microspheres sized from 40 to $80 \mu \mathrm{m}$ can be regularly arranged in arrays on $\mathrm{Al}$ alloy surface after free fall. It is experimental verified that formation mechanism is based on the gravity-driven rolling of microspheres from the top of micro-ridges caused by pulsed laser to the area of laser untreated, and then forming an array between micro-ridges. Also, approximate $26 \mu \mathrm{m}$ height and $50 \mu \mathrm{m}$ widths are considered as parameter thresholds of micro-ridges for induction of decent microsphere arrays. Hence, this low-cost and time-saving particle arrangement technology is important and meaningful to lower technical requirement of several particles-involved nano- and near-field optical technologies.

\section{Acknowledgements}

The authors gratefully acknowledge the financial support provided by the Sêr Cymru National Research Network in Advanced Engineering and Materials (ref: NRNF66 and NRN113) and the Knowledge Economy Skills Scholarships (KESS 2, ref: BUK289).

\section{References}

[1] M. Brust, C. J. Kiely, Colloids Surf. A 202, 175 (2002)

[2] S. D. Evans, S. R. Johnson, Y. L. Cheng, T. Shen, J. Mater. Chem. 10, 183 (2000)

[3] H. Wohltjen, A. W. Snow, Anal. Chem. 70, 2856 (1998)

[4] L. Li, T. Zhai, H. Zeng, X. Fang, Y. Bando, D. Golberg, J. Mater. Chem. 21, 40 (2011)

[5] W. Wu, A. Katsnelson, O. G. Memis, H. Mohseni, Nanotechnology. 18, 485302 (2007)

[6] Y. Li, H. Xin, X. Liu, Y. Zhang, H. Lei, B. Li, ACS Nano. 10, 5800-5808 (2016)

[7] V. Pacheco-Peña, I. V. Minin, O. V. Minin, M. Beruete, Photonics. 3, 10 (2016)

[8] F. Juillerat, H. H. Solak, P. Bowen, H. Hofmann, Nanotechnology. 16, 1311-1316 (2005)

[9] M. Grzelczak, ACS Nano. 4, 3591-3605 (2010)

[10] A. van Blaaderen, R. Ruel, P. Wiltzius, Nature. 385, 321 (1997)

[11] J. P. Hoogenboom, C. Rétif, E. de Bres, M. van de Boer, A. K. van Langen-Suurling, A. van Blaaderen, Nano Lett. 4, 205 (2004)

[12] D. G. Choi, H. K. Yu, S. G. Jang, S. M. Yang, Chem. Mater. 15, 4169 (2003)

[13] Y. Cui, M. T. Björk, J. A. Liddle, C. Sönnichsen, B. Boussert, P. Alivisatos, Nano Lett. 4, 1093 (2004)

[14] A. Ashkin, Phys. Rev. Lett. 24, 156-159 (1970)

[15] A. Ashkin, J. M. Dziedzic, J. E. Bjorkholm, S. Chu, Opt. Lett. 11, 288-290 (1986)

[16] J. A. Rodrigo, T. Alieva, Optica. 2, 812-815 (2015) 
[17] S. Darwich, K. Mougin, A. Rao, E. Gnecco, S. Jayaraman, H. Haidara, Beilstein J. Nanotechnol. 2, 85-98 (2011)

[18] S. R. Pettersen, A. E. Stokkeland, H. Kristiansen, J. Njagi, K. Redford, D. V. Goia, Z. Zhang, J. He, Appl. Phys. Lett. 109, 043103 (2016)

[19] I. Etsion, J. Tribol. 127, 248-253 (2005)

[20] I. W. Boyd, Laser Surface Processing and Characterization, 1st edn. (Elsevier, Amsterdam, 1992)

[21] W. M. Steen, Laser material processing, 3rd edn. (Springer, Berlin, 2003)

[22] Y. Hu, Z. Yao, Surf. Coat. Tech. 202, 1517-1525 (2008) 